Article

\title{
A Framework of Action for Implementation of Industry 4.0. an Empirically Based Research
}

\author{
Artur Pollak ${ }^{1}$, Agata Hilarowicz ${ }^{2, *}$ (), Maciej Walczak ${ }^{1}$ and Damian Gąsiorek ${ }^{3}$ (I) \\ 1 APA Group, Tarnogórska 251 Street, 44-105 Gliwice, Poland; artur.pollak@apagroup.pl (A.P.); \\ maciej.walczak@apagroup.pl (M.W.) \\ 2 Faculty of Social Sciences, University of Silesia, Bankowa 11 Street, 40-007 Katowice, Polan \\ 3 Faculty of Mechanical Engineering, Silesian University of Technology, Konarskiego 18A Street, \\ 44-100 Gliwice, Poland; damian.gasiorek@polsl.pl \\ * Correspondence: agata.hilarowicz@us.edu.pl
}

Received: 3 June 2020; Accepted: 14 July 2020; Published: 18 July 2020

\begin{abstract}
Background: In the face of changes taking place as a result of the increasing digitization, automation, and robotization of life and the economy, questions regarding the essence of the functioning of modern enterprises and about the emerging new pattern of operation seem to be more and more relevant. Aim of the article: The article focuses on the issues connected with implementation of Industry 4.0 in enterprises, the difficulties involved, and the limitations and challenges that management is facing in the process. Materials and Method: The advantage of the study is its empirical nature. The participants were 39 Industry 4.0 experts from various Polish companies that have participated. At the same time, the aim has been to synthesize theory and practice and to draw attention to potential changes in the area of improvement of the economic results of enterprises that may result from Industry 4.0. Results: The research identified limitations and challenges enterprises may face in connection with the implementation and subsequent stages of development of Industry 4.0 from the practical point of view. Conclusions: Industry 4.0 is an innovative approach to generating a new quality of production. It requires, however, careful and thorough observation of the process already at the preparation stage.
\end{abstract}

Keywords: Industry 4.0; implementation of Industry 4.0; limitations and challenges of Industry 4.0

\section{Introduction}

Industry 4.0 (I4.0) is becoming increasingly important both as a construct and a trend toward technological changes in industry and the economy as a consequence of digital transformation. It is often defined by the prism of consolidated modern technologies, which at the same time allow for convergence between industrial and business components and production models and internal processes of enterprises [1]. The use of digital technologies and a change in the company's strategy assume the possibility of cost-effective personalized production in response to the individual needs of customers [2-4]. The specificity of I4.0 results from process automation, system integration, Internet of Things (IoT), Internet of Services (IoS), and the development of cyber-physical systems (CPS) [2,4-8]. These systems merge the real and the virtual world and enable data to be transferred between people and objects along the entire value chain in real time [7,9].

Smart connections of autonomous, complete structures consisting of machines and self-configuring real-time production systems are expected to lead to dramatic improvements in efficiency, better resource management and greater flexibility and adaptability of products and services [7,10], decision-making efficiency, better risk control [1], and a greater business outreach [11]. 
The literature on I4.0 anticipates significant future benefits, most significantly value creation in many areas that contribute to global sustainable development, including economic, social, and ecological dimensions [12]. The overall efficiency of industrial value creation is expected to increase, along with ecological and social benefits, e.g., reduced energy and material consumption, waste reduction, and adaptive working environments $[7,13,14]$. In this context, consideration is also given to the relationship between I.40 and sustainability.

The starting point for I4.0 is the concept of the smart factory (SF), the smart industry (SI), the smart automation (SA), and advanced manufacturing $[4,6]$. SF connects the digital world of information technology with the physical world of operational technologies, which is referred to as IT/OT convergence [1]. This is the basis for individualized production tailored to the needs and requirements of consumers while maintaining the advantages of economies of scale [3].

The transformation towards I4.0 is a noticeable phenomenon in many countries, but its range and intensity vary. In managerial practice, detailed research has not yet been documented to a sufficient extent, as a comprehensive implementation of I4.0 is still in works $[7,12]$.

In Poland, empirical studies on constraints and challenges relevant to the implementation of I4.0 in companies are scarce. This reflects the relatively low level of I4.0 development despite the increasing digitization of the economy and industry. At the current stage of development, it is still difficult to talk about the unequivocal consequences of implementing I4.0. However, it is worth noting the opinions of researchers and practitioners who outline some emerging tendencies and point to various limitations at the initial stages of business transformation towards I4.0, as well as to the difficulties, risks, and challenges that appear after the implementation phase.

The purpose of the article is to present the results of the piloting research conducted among I4.0 experts regarding industry specifics and attributes, issues related to the preparation of companies for I4.0, including limitations appearing early on in the process, and difficulties arising in the later stages. The pilot study aimed at collecting data to provide guidelines for future substantive research adapted to Polish conditions, using observational data to create the right research tool. An additional added value of the article is the synthesis of I4.0 theory and practice.

It is assumed that these considerations will contribute to a deeper understanding of what I4.0 is and will draw attention to those aspects that should be taken into account during development and training stages as well as during the implementation and practice of I4.0.

The article is organized as follows: Section 2 ("Theoretical Framework") gives a brief overview of the concept of I4.0, its attributes, and most frequently encountered constraints and challenges. Section 3 ("Materials and Method") describes the research design and methodology. The main empirical results are presented in Section 4 ("Results"), followed by a discussion and conclusions in Sections 4 and 5 ("Discussion and Conclusions"). Conclusions concern the main findings along with limitations and recommendations for future research.

\section{Theoretical Framework}

The term "industry 4.0" was used for the first time by German scientists in 2011 and referred to the increasing automation of industrial processes and the connection of the physical world with the virtual world $[2,4]$. In the same year it was adopted and then disseminated by the German Government as a strategy for the development of German industry $[4,11,13,15-17]$. In the following years, the concept evolved and began to be used in a broader context as an expression of the so-called fourth industrial revolution reflecting all the complex technological changes used in organizations $[3,4,6]$. Currently, these terms are used interchangeably. However, there is not one universally recognized definition of I4.0 [6,7]. Analyzing the literature on the subject, it can be seen that the understanding of the term "I4.0" is based on a combination of interconnected characteristics distinguishing specific practices in manufacturing and relevant sectors of the economy that result from the use of advanced digital technologies. The most frequently mentioned technological solutions, which are driving forces or pillars of I 4.0 and at the same time determine its characteristics, are IoT and IoS, Cloud Computing 
(CC), Big Data Analytics (BDA), additive technology (AT) and 3D printing, autonomous robots, and Augmented Reality (AR) [7,11,13,15,17-19]. Integrated technologies create a specific ecosystem in which there is a continuous exchange and analysis of data between various entities, i.e., people, machines, devices, robots, and sensors in real time [13]. The essence of such transformation is the mutual interaction of CPS (sensors, machines, workpieces, and information systems) using standard internet protocols along the value chain outside one enterprise $[4,9,20]$. This creates completely new conditions for the functioning of companies and their employees. It gives, among others, the ability to combine data from external and internal sources to streamline decision-making processes, anticipate failures, and configure and adapt to changes [21]. It affects the development of digital skills by improving the integration and management of resources in organizations, promotes risk control, and promotes a better understanding of the impact of technology on localized production [1]. Acater and Cruz-Machado [4] draw attention to the technical connection of CPS with production and logistics as well as the use of IoT and IoS in industrial processes. In this approach, I4.0 appears as an interoperable production process, integrated, adapter and service-oriented, which is correlated with algorithms and other advanced technologies [4]. Koch and others [21] in the report of the consulting company PwC cite the definition according to which I4.0 is understood as (...) a new level of organization and control over the entire value chain of the product life cycle, (...) focused on the increasingly individualized demands of customers. The product life cycle length was defined as the period from product design through development, production, and delivery of the product to the customer, to recycling as the final phase. Access to relevant real-time information during all the phases was considered as a basic condition for I4.0.

Wagner, Herrman, and Thiede [3] offer a slightly broader perspective, identifying I4.0 with a certain industrial vision enabling for the connection of people and things at anytime, anywhere, with any person and anyone, preferably using any path, network, or service.

Similar approaches have been developing worldwide, so I4.0 can be defined as a real-time, intelligent, horizontal, and vertical networking of people, machines, objects, and information and communication systems with the aim of dynamically controlling complex systems $[7,8]$.

Despite the definition discrepancies, the common characteristic attributes of I4.0 can be identified from various studies. The main features of I4.0 include: horizontal integration through value networks to facilitate inter-corporation collaboration, vertical integration of hierarchical subsystems inside a factory to create a flexible and reconfigurable manufacturing system, and end-to-end engineering integration across the entire value chain to support product customization [22].

The United Nations Industrial Development Organization (UNIDO) [1] points to the following nine attributes of I4.0: interoperability, virtualization, decentralization, real-time capability, service orientation, modularity, convergence, cost reduction and efficiency, and mass personalization. Interoperability is identified with the so-called ubiquitous connectivity $[3,5,6]$ and global communication using CPS systems - that is, an extensive communication network between physical objects and various entities, companies, factories, suppliers, logistics, resources, and customers. It can also be understood as connected value networks transformed into digital ecosystems [19]. Virtualization involves creating a virtual copy of an intelligent factory (physical world) by combining sensor data with virtual installation models and simulation models [2]. It also means the possibility of virtual prototyping of products. Decentralization is associated with high the autonomy of CPS systems, which make their own decisions and reproduce locally (using 3D) [1,4]. Production systems are connected vertically with business processes in factories and enterprises, and horizontally with spatially dispersed value networks that can be managed in real time-from order placement to outbound logistics [1,4]. Real-time capability refers to instant access to information and key analyses [1] connecting, for example, areas of machine operation, production volume, product quality, failure rate, and availability of equipment. Intelligent data are collected and processed throughout the entire product life cycle [1]. Service orientation is also referred to as responsive manufacturing and corresponds to the so-called personalizing of the final product, i.e., adjusting production to meet expectations of a customer/consumer, who should 
also be involved in the product design phase. Modularity is understood as flexible adaptation of SF to changing requirements by replacing or extending individual modules [1]. The convergence results from the above-mentioned ubiquitous connectivity using intelligent software and instant access to data and analysis. Thanks to this, barriers of convergence between industries, disciplines, and worlds (biological, physical, virtual) disappear [1].

The sequence of the above features also includes the expected cost reduction and efficiency improvement combined with the optimization of flexible supply chains and distribution models, and the effective use of machinery and equipment [1].

The functions and the expected benefits for enterprises result from the technology used and, consequently, from the I4.0 attributes. It is believed that the implementation of the I4.0 concept, in addition to reducing costs and maximizing efficiency, should, among others, increase design and production flexibility, improve accuracy and product quality, reduce operation time, improve resource allocation and material management, enable appropriate control of processes, and introduce innovative solutions [1,4]. At the same time, attention is paid to the possibilities of optimizing the use of factors of production-land/environment, labor, capital, or information—and optimizing the use of resources such as energy or water.

The aim of I4.0 is to create fully digitalized, networked, intelligent, and decentralized value creation networks [7]. The main areas of the impact of I4.0 include: competitiveness and business models [13,23-26]; efficiency and performance [8,27-29]; workforce-related factors [8,30-33]; and consumer needs [12,22].

\subsection{Constraints and Challenges of Industry 4.0 and the Context of Sustainability}

Given the global nature of the changes and their magnitude, including the huge differences between economies, enterprises, and technologies used, it seems justified to relate the constraints and challenges facing I4.0 to its specific dimensions, i.e., driving forces, areas of application, and impact. The risks and challenges associated with the absorption of digital solutions by enterprises are diverse. The most frequently mentioned are the standardization of systems, changes in work organization [34,35], data security and investment costs, stability of technical infrastructure and sensitivity of its systems, increased competition, higher investment requirements, difficulties in recruiting qualified personnel, the adoption of appropriate legal frameworks, and changes in business models [2,22,32].

Generally, I4.0 constraints and challenges can be classified in relation to different areas, e.g., economic, technological, organizational, ethical, political-legal, and social, and analyzed on a case-by-case basis [2,7]. Referring to the idea of sustainable development and adopting the Triple Bottom Line approach (TBL), the factors driving the development of I4.0 should be looked at from an economic, ecological, and social standpoint [36]. Each dimension represents a necessary, but not sufficient on its own, condition for achieving sustainability. When organizations do not support all of these dimensions, they do not act sustainably. This perspective is currently used in many studies $[8,12,36,37]$. It also allows for adopting a multi-faceted, diverse view of companies of various sizes, industry sectors, and the role of the company as a supplier or user of Industry $4.0[8,36]$. The concepts of sustainability as well as I.4.0 have received increasing global attention from the public, academic, and business sectors. In this context an interesting research area is the impact of I4.0 implementation on sustainable development. The analysis of the limitations and challenges that make up the I4.0 capabilities, therefore, becomes an important element of consideration in the context of sustainability. Economic constraints and challenges will be primarily related to the costs incurred at a specific stage of implementation and maintenance of I4.0 and to the Return on Investment (ROI). It is assumed that I4.0, especially, at the implementation phase, requires large investments, leading to a high implementation barrier [7]. Economic feasibility plays significant role for small businesses. Another issue may be the difficulty in determining the likelihood of succeeding [7]. Next, economic concern is the possibility of the loss of a competitive advantage through diminishing business models [7]. Opinions on the business models issue, however, are divided. On the one hand, business 
models are disappearing; on the other hand, new models are created as a result of database-based products and services [31]. From an economic point of view, an aspect of value optimization, due to the transparency of processes and networking [36,38], is also pointed out. Logistics costs can be reduced due to the transparency of processes [39]. The impact of I4.0 on the increase in efficiency and flexibility of production processes, and on the quality and individuality of products and services, is emphasized [1,2].

Difficulties and challenges in technology result from the convergence of many streams/factors while organizational challenges relate to new forms of work and cooperation [14]. Challenges in the political and legal area are due to the lack of and/or insufficient regulations.

When referring to the ecological aspects of I4.0, it is believed that the technologies associated with it have the unique potential to unlock environmentally sustainable manufacturing [36]. It means that I 4.0 can help reduce greenhouse gas emissions by reducing the energy consumption of the industrial value chain and by improving product life cycle management and recycling processes. The use of process simulations and smart energy management is needed to achieve the above goals. [7,35]. Bonilla et al. notes that, real environmental performance requires integrating I4.0 goals with the ecological ones in an eco-innovation platform [32].

Social sustainability encompasses aspects like job satisfaction, quality of life, social inclusion, solidarity, equity, and justice in the distribution of goods and services, and equal opportunities in education. Social constraints stem mostly from people's mentality and awareness, and from the impact of new conditions on privacy, including the possibility of losing a job [7]. People's perception and attitude towards machines and devices affects the environmental and organizational context. In I4.0, the specific nature of human interaction with robots and AR forces changes in the working environment and how the work is performed [40,41]. For example, intelligent assistance systems and adequate human-machine interfaces can lead to increased employee satisfaction [7,42]. At the same time, the remote nature of work, communication in a visual environment, and frequent changes of roles and projects, require a new set of competences on the part of employees, and the ability to adjust methods of managing the work process, techniques, and tools on the part of employers. In the social dimension, it is discussed how occupational profiles and working habits will change, how some tasks will fall to autonomous systems, and how the automation of simple tasks will continue to progress, which can lead to job losses [43]. There is broad disagreement as to whether I4.0 will lead to an increase or decrease in jobs. Statements in this context are disparate, and sometimes even contradictory [7]. The social challenges are related to a necessity for additional training and the requalification of the workforce, especially in routine or simple occupations [44]. Some of the mentioned challenges can lead to a decreasing acceptance of the existing workforce and impede organizational transformation [7]. The above characteristics contribute to obstacles at the enterprise level, along with other potential challenges in the production process resulting from outdated technologies and processes, the necessity of ensuring data security, data ownership issues (due to the increasing importance of digital platform providers and the blurring of company boundaries in connected value networks transformed into digital ecosystems), and the protection of industrial secrets [7].

Santos and others distinguish four categories of driving forces of I4.0, which in addition to the already mentioned organizational and technological factors, also include innovative and operational factors [19]. The limitations and challenges in the innovation area are related to the development of new business models and to the creation of innovation networks. Operational factors have to do with the improvement of operational efficiency. They can also be analyzed in relation to the absorption phase of digital technologies (implementation, feasibility).

Vermeulen, director of Instrktiv [18] points to six dimensions in which analyses regarding the implementation of I4.0 should be carried out. These are: (1) Strategy and business model—creating the right strategy for I4.0; (2) Technology and Systems-using technology to achieve optimal results; (3) Governance and Risk management-maximizing benefits while avoiding risk; (4) People-educating and leading employees so they can adapt to the new industrial standard; 
(5) Operational excellence-gaining a competitive edge through technology; and (6) Customer experience-improving customer experience.

A useful tool in this area of analyses is also the assessment of the so-called enterprise digital maturity, e.g., Deloitte's digital maturity model with five core dimensions (Customer, Strategy, Technology, Operations, Organization, and Culture) [12].

\subsection{Research Questions}

The literature analysis shows numerous constraints and the challenges of the implementation phase of I4.0.

The study answers the research question of how SMEs and large manufacturing companies in the region of Silesia (Poland) perceive the constraints and challenges in the context of transformation toward I4.0?

More specifically the following research questions (RQ) have been formulated:

RQ1: Which of the perceived constraints of I4.0 implementation are critical?

RQ2: Are there differences in the perception of difficulties at the different stages of development of I4.0 (implementation phase and subsequent feasibility)?

RQ3: Is it necessary to use all I4.0 pillars to include the company in I4.0?

RQ4: Which technology is the most important from the point of view of I4.0 development?

\section{Materials and Method}

The aim of the study was to identify the constraints and challenges that arise within the framework of I4.0. It is assumed that knowledge and beliefs on this subject determine future decisions and behavior [45].

This study is a pilot study, preceding the main research. The rationale for conducting it is the fact that I4.0 in Poland is still at a low level of development, and the mechanisms characteristic for this subject of the study are little known. Hence, it was carried out on a small scale. The selection of the sample was deliberate and, due to this, not representative. The pilot study reported in this article may be viewed as a combination of the two types of pilot studies used in social sciences: feasibility studies, and the pre-testing [46]. The study had the character of the first contact with the examined reality; we wanted to assess the respondents' knowledge about I4.0, identify the limitations and challenges associated with its implementation, as well as check the overall response to the subject matter and evaluate the research method (determine how to measure I4.0) for future, expanded research. It was also important to gather information on the studied environment and study population in order to be able to formulate a proper research plan and tool for the needs of further, expanded research. This research design is particularly suitable in this context.

To explore the potential constraints and challenges of I4.0, a diagnostic survey method using a well-structured questionnaire was applied. At the same time, the aim has been to synthesize theory and practice and to draw attention to the possible improvement of the economic results of enterprises that may result from I4.0. The study was based on a survey conducted with business practice experts, who participated in the implementation of the I4.0 practices in their enterprises.

This approach was used for a number of reasons [47,48]. First, survey is a commonly used method in the areas of social sciences and management [49]. A precise questionnaire is an essential part of collecting informative details from the concerned respondents in a short amount of time. This is also helpful in getting the knowledge of past and present actions. An effective questionnaire can be an objective means of gathering data from people who initiate and introduce changes in organizations about their knowledge, beliefs, attitudes, and behaviors. Secondly, research questions were constructed based on the investigators' current knowledge in the area of I4.0 implementation. Concise objectives helped determine the critical information needed. Every question was analyzable, interpretable and provided relevant information. Additionally, questions used previously in similar situations were included to increase the reliability of the questionnaire. 
The author's original questionnaire was used in the research. The questionnaire consisted of 9 items regarding the perception of the concept of I4.0, characteristics of I4.0, constraints and challenges at the implementation stage and the later feasibility stage, and assessments of the improvement of economic indicators of the enterprise as a result of I4.0. The first 6 were open-ended questions, without a list of responses to choose from, and the remaining 3 were closed-ended questions with a finite set of answers. Open-ended questions allowed respondents to give free-form answers, which was important in the context of complex, new, and evolving phenomena.

The following questions were asked:

1. What best describes I4.0?

2. What features distinguish the 4.0 factory most from other factories?

3. What others do not know about the specifics of implementing I4.0?

4. What are the most interesting technologies that make up I4.0?

5. Which was the biggest constraint/challenge when implementing I4.0 in your enterprises?

6. What were the biggest restrictions in the feasibility stage of I4.0 (later stages of development) in your enterprise?

7. Do you believe that the implementation of I4.0 gives your enterprise the opportunity to improve its economic performance?

8. Do you think that piloting I4.0 deployment is important?

9. Do the co-workers know the concept of I.4.0?

The study was conducted in November and December 2019.

The research involved 39 subject matter experts: managers, business owners, and specialists responsible for the process of implementing innovations in enterprises, including those actively involved in the creation of I4.0. Respondents come from Upper Silesia-the most industrialized region in Poland, where the automotive industry is dominant. They were recruited from among MBA students with an I4.0 focus and from the members of the Industrial Transformation Team at the Ministry of Development of the Republic of Poland, participating in the New Economy Forum. Among the goals of the Industrial Transformation Team is to develop initiatives to digitally transform the economy, in line with the principle of sustainable development, and to put forward specific proposals for action to digitally develop industry [50].

Distribution of participants was as follows: 15 (38\%) represented large companies (over 250 employees), 10 (26\%) worked in medium-sized companies (between 250 and 50 employees), 7 (18\%) were employed in small companies (up to 50 employees), and $2(5 \%)$ in micro (less than 9), while 5 respondents $(13 \%)$ did not provide information on the size of the enterprise in which they worked. The respondents were mainly representatives of the manufacturing $(34 \%)$ and service industries e.g., printing and rail transport (13\%), while 9 people $(21 \%)$ did not provide information about the company. A total of 31 respondents (79\%) were either company owners or managers.

A homogeneous test procedure was adopted. Participants were informed about the purpose of the research, assured of anonymity and instructed on how to complete the questionnaires. Completing and submitting the questionnaire indicated agreement to participate in the study.

\section{Results}

\subsection{Perception of the I4.0 Framework}

Respondents closely identify the concept of "I4.0" as well as its attributes with modern technologies. When asked "what best describes I4.0" the vast majority (59\%) indicated IoT, slightly more than half $51 \%$ pointed to $\mathrm{BDA}$, and $26 \%$ mentioned automation and robotization. Some of the respondents referred to innovation (10\%) and about $8 \%$ drew attention to the aspect of cooperation between people and machines. Interestingly, the smallest percentage described I4.0 through Artificial Intelligence. Figure 1 shows the understanding of the term I4.0. 


\section{Innovativeness \\ Adapted to companies Al \\ Data Analytics \\ Human-machines cooperation \\ Automatization \\ Digitalization}

Figure 1. Perception of I4.0.

\subsection{Attributes of I 4.0}

As far as features distinguishing the I4.0 factory from other factories, BDA (58\%) was in the first position, then automation and robotics (26\%) and IoT (23\%). In addition to technology, other attributes such as innovation and competitiveness ( $5 \%$ each) have also been mentioned. A detailed distribution of responses is shown in Figure 2.

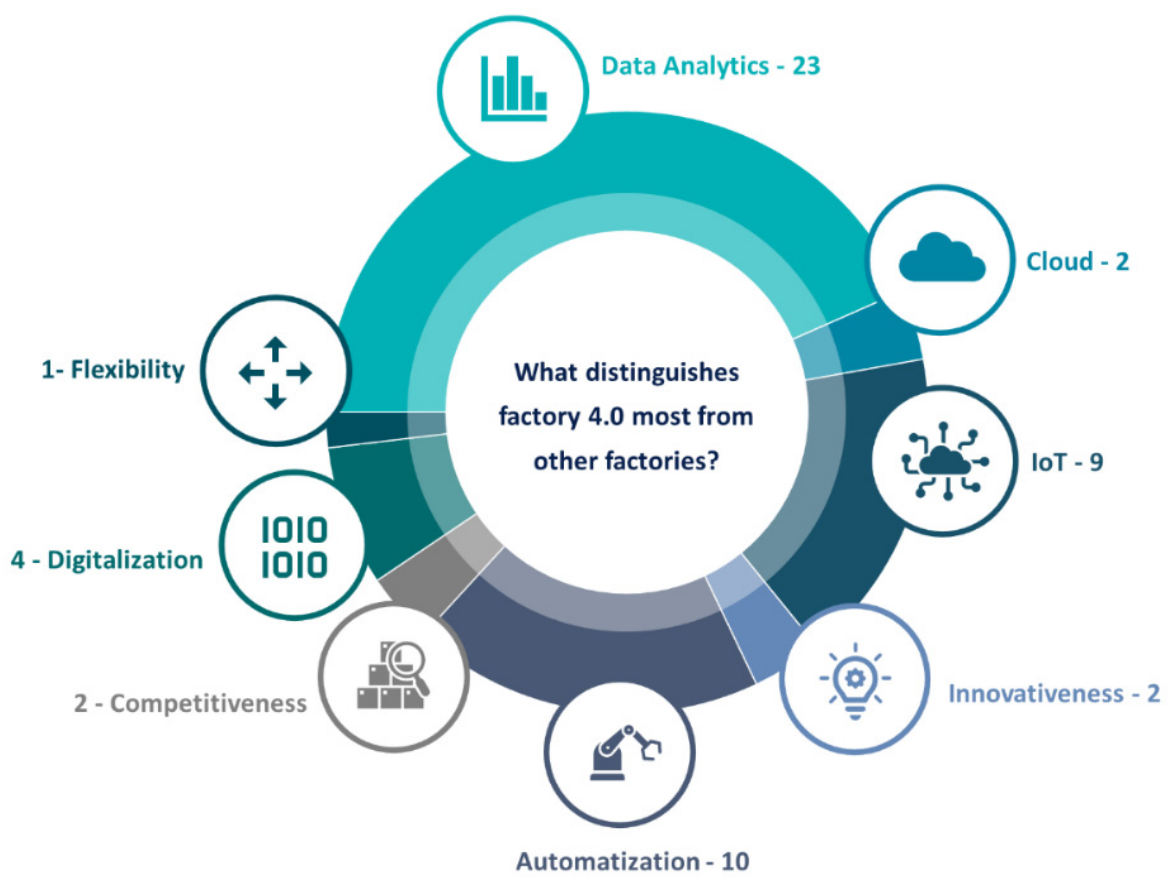

Figure 2. Attributes of I4.0.

\subsection{Lack of Knowledge about I4.0 and Its Implementation}

Respondents note that knowledge about possible benefits, the mechanism of action, and technological requirements related to the implementation of I4.0 is very limited. The most frequent responses to the question "What others do not know about the specifics of implementing I4.0?" were "It is profitable" and "It is possible to integrate existing devices onto processes". Those two were given by $23 \%$ of respondents. Slightly fewer indicated that "System solutions are available" $(18 \%)$, "It is scalable" (14\%), and "What technologies exist" (14\%). A detailed distribution of responses is shown in Figure 3. 


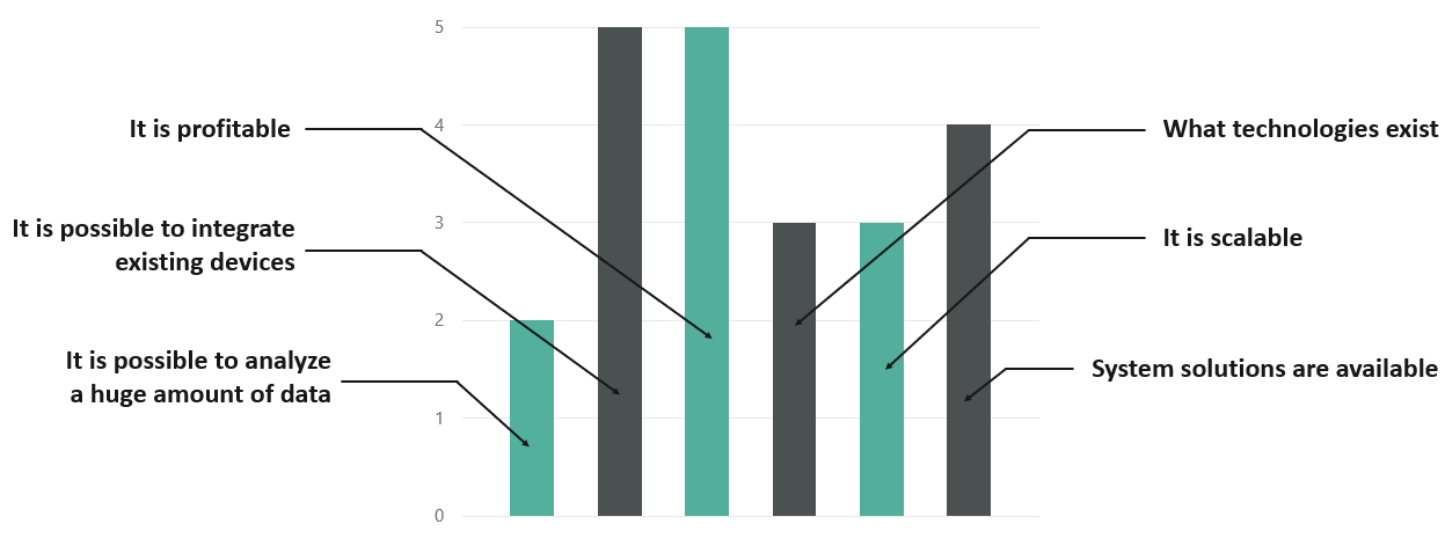

Figure 3. Lack of Knowledge About I4.0 and Its Implementation.

\subsection{The Most Interesting Technologies in I4.0}

According to respondents the most interesting technological solutions for I4.0 were BDA and IoT ( $36 \%$ of responses each), followed by CC and AI (23\% each), automation (15\%), and 3D printing (Figure 4).

\section{Cloud \\ Al 3D Printing \\ Data Analytics \\ Automatization \\ Digitalization}

Figure 4. The Most Interesting Technologies in I4.0.

\subsection{Constraints and Challenges in the Implementation and Feasibility Stages}

Constraints of Implementation. The most frequently mentioned limitations at the implementation phase of I4.0 are costs (38\%), and employee's attitude to I4.0 and lack of experts ( $26 \%$ of indications each). Further distractors also include: no return on investment $(10 \%)$ and the lack of standardization (5\%). Respondents also stress that I4.0 is not the solution suitable for all companies (5\%). Further restrictions also include lack of time, lack of equipment, and lack of technological knowledge $(2.5 \%$ of indications each) (Figure 5).

Restrictions in the later stages. During later stages, the first constraint mentioned was automation (36\% of indications) followed by the human factor issue-including both attitudes towards I 4.0 and issues related to the training of workers ( $21 \%$ of indications each). Other difficulties included habits and no return on investment (10\% of indications each), lack of standardization and problem with IoT ( $8 \%$ each), and data analysis (5\%). Respondents also raised concerns about uncontrolled data leakage $(5 \%)$, the possibility of job losses (3\%), and difficulties in installing new software (3\%) (Figure 6). 


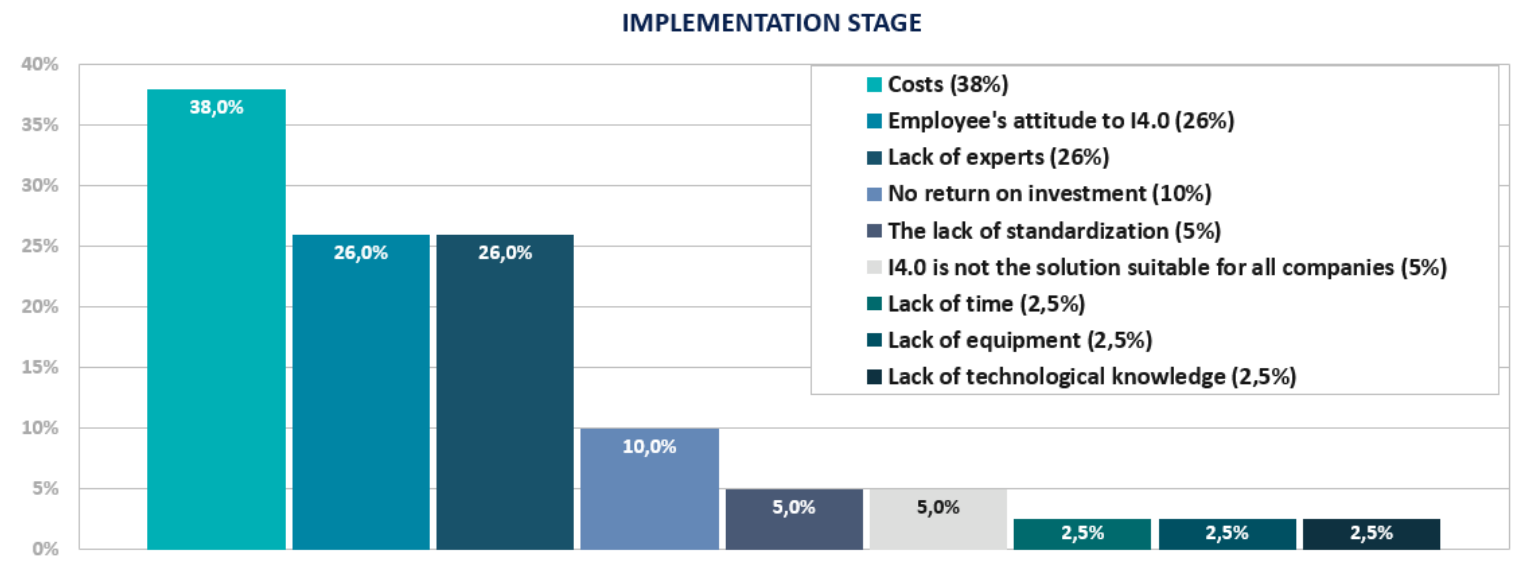

Figure 5. Constraints of Implementation Stage.

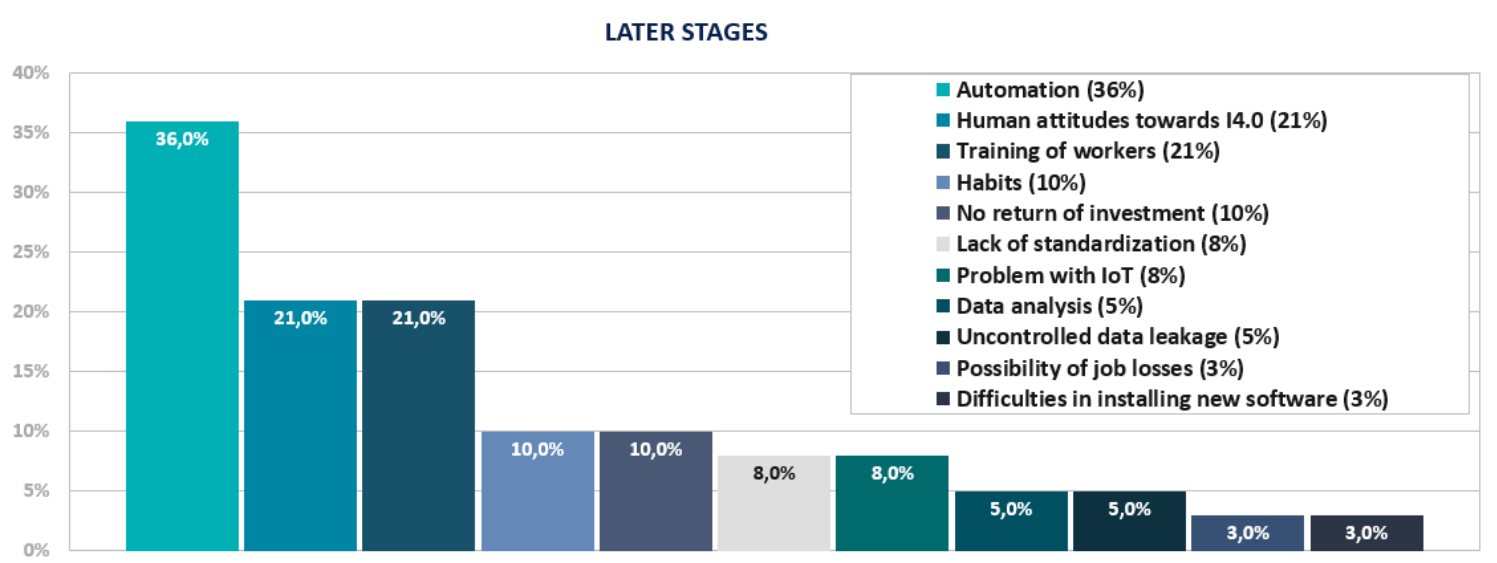

Figure 6. Restriction in the later stages.

\subsection{Impact of Digital Transformation on the Business Ecosystem}

To assess beliefs about the positive nature of economic changes in enterprises resulting from the introduction of the idea of I4.0, the question was formulated as follows: "Evaluate to what extent you believe that the concept of Industry 4.0 gives the opportunity to improve the economic indicators of the enterprise." The task of the respondents was to mark the answer on a 7-point scale, where 1 meant-I do not believe at all-and 7-I believe very much. In total, 37 people gave the answer, and 2 did not indicate an answer. The results were analyzed in the SPSS program ver. 26. They are shown in Table 1.

Table 1. Descriptive statistics-frequency.

\begin{tabular}{ccc}
\hline Indicated Response & Frequency & Percent \\
\hline 3-To a Small Extent & 1 & 2,6 \\
4-Average & 3 & 7,7 \\
5-To a Relatively Large Extent & 10 & 25,6 \\
6-To a Large Extent & 16 & 41,0 \\
7-To a Very Large Extent & 7 & 17,9 \\
\hline
\end{tabular}

Note: $N=37$.

Analysis of the results of the whole group $(M=5.68 ; \mathrm{SD}=0.973)$ indicates that respondents to a large extent show confidence in the fact that concept I4.0 contributes to improving the functioning of processes, which translates into increased efficiency and improved competitiveness. In total, 16 people $(41 \%)$ chose the "to a large extent" answer. Among the respondents, 10 and 16 people indicated the answer to a relatively large extent and to a large extent, respectively. 


\subsection{Importance of the I4.0 Piloting}

Pilot projects are often utilized in Industry 4.0. They offer a viable tool of conducting and analyzing a new way of managing a specific technological process combined with modern technology. The question about the validity of conducting pilot projects was formulated as follows: "Do you think that the pilot study on I4.0 implementation is important?". Respondents were to mark the answer on a 7-point scale, where 1 meant not relevant, and 7 meant relevant to a very large extent. Results are shown in Figure 7.

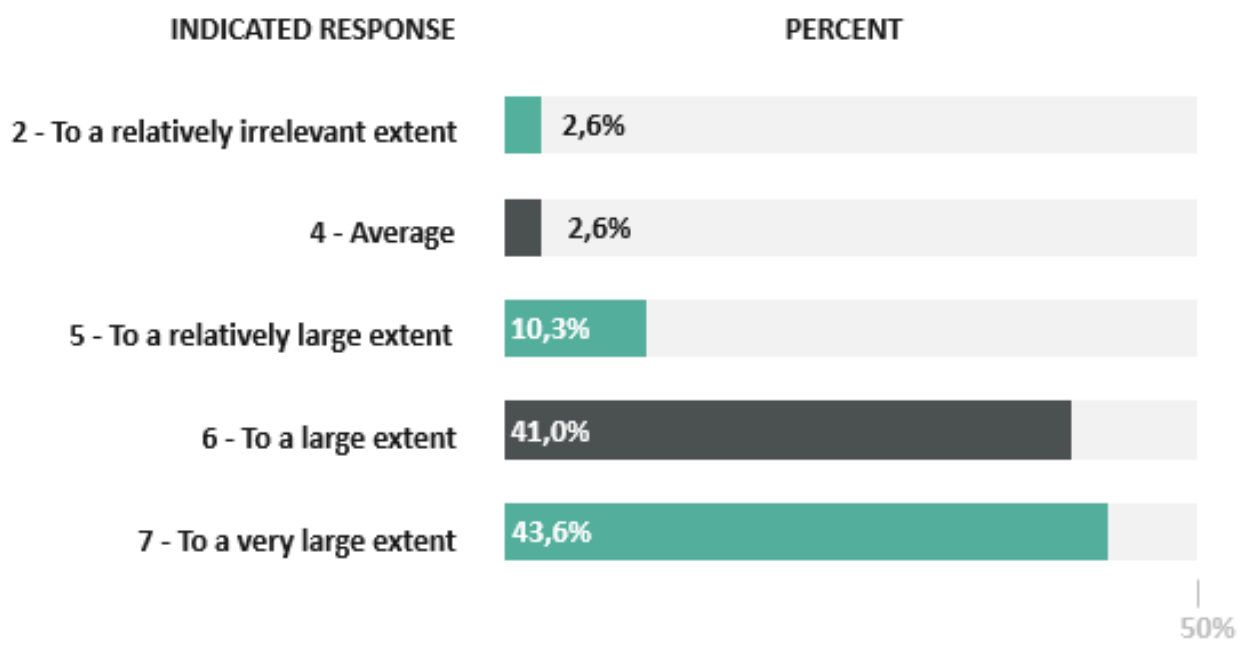

Figure 7. Importance of the I4.0 piloting.

\subsection{Knowledge of the Concept of I4.0 by Co-Workers}

A response format to the question "Do your co-workers know the concept of I.4.0?" was, also, a 7-point scale, where 1 meant "not familiar with", and 7 meant "familiar to a very large extent". A total of 39 people responded (Figure 8).

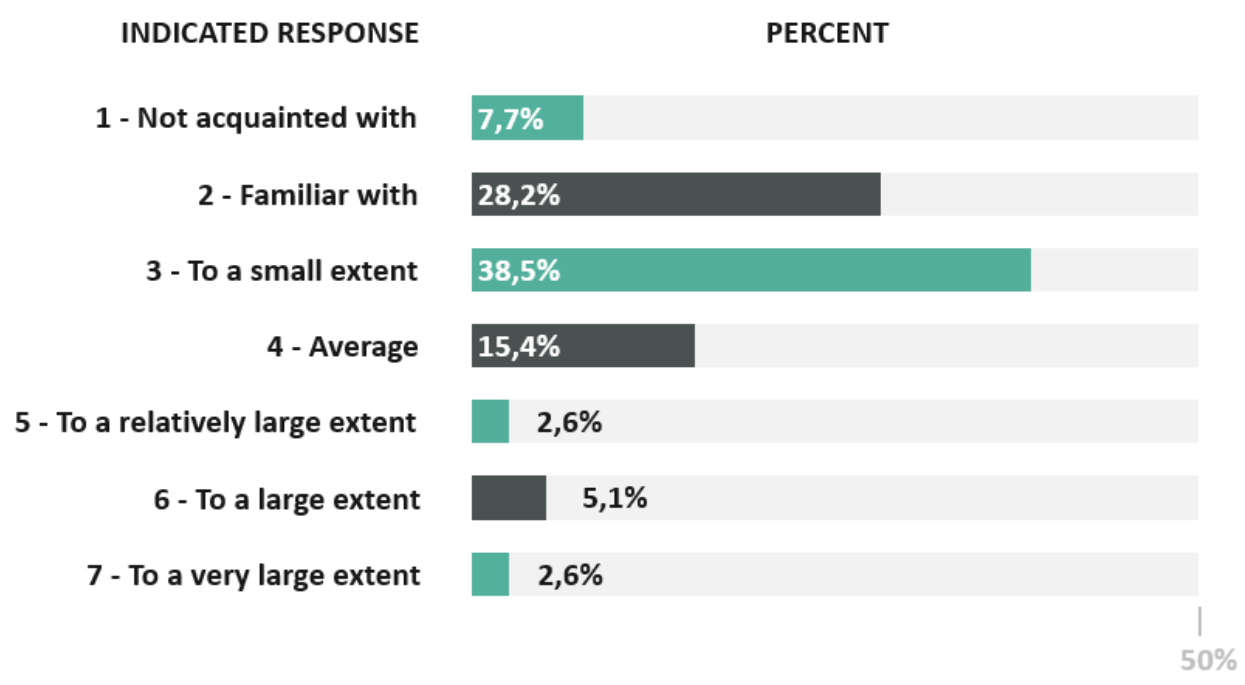

Figure 8. Knowledge of the concept of I4.0 by co-workers.

\section{Discussion and Conclusions}

This research explores the constraints and challenges that are considered as important for the implementation and feasibility stage of I4.0 within a sample of manufacturing companies located in the region of Upper Silesia (Poland). Study participants have been actively involved in the transformation 
of the production processes at the companies they work for. The very consent to the completion of the survey can be already seen as a sign of their positive attitude toward the concept of I4.0. The results of the empirical research show a high convergence with the theoretical deliberations.

Respondents had no problem with pinpointing the limitations and challenges of I4.0. With respect to the RQ1 formulated in the present paper, the overall analysis of the sample indicates that companies in general consider economic limitations as well social limitations to a higher extent to other limitations at the implementation stage of I4.0. The main obstacles toward I4.0 transformation are the cost of the implementation process and employees' attitudes and the lack of experts. This may be due to general ignorance of I4.0, fear of changes and their consequences, e.g., loss of job or the need to complete qualifications [7]. This evidence about economic limitations in the implementation stage of I4.0 is aligned to the existing literature and studies from other countries [36].

Regarding RQ2, we conclude that during later stages, the first critical constraint is of technical and organizational character. The economic factor is less important. However, again, the human factor is one of the major barriers, including both attitudes toward I4.0 and the lack of employee's competence. With regard to the differences in the perception of problems at particular implementation process stages of I4.0, they are visible but they mostly concern the assessment of importance and mutual shifting of financial, human, and technical factors. In the feasibility stage, the problems with automation and employees' attitudes toward completing qualifications (training) are most important. Findings show that, the main barriers to I4.0 include the lack of a skilled workforce [12], lack of managerial competences [12], costs or lack of financial resources [12,17], human mentality [12], and technology adaptation. Literature includes a change of competences and the need to provide training for employees as additional significant challenges the I4.0 is facing $[1,15,16]$.

Not only did the respondents emphasize the strict link between I4.0 and the technologies, but they also identified the most important ones and those most used in their companies. They consider IoT and BDA as the technological basis for I4.0. According to the responses regarding RQ3 and RQ4, a company does not have to use all technological pillars to be considered an I4.0 company. The most important technological solutions include BDA, automation, and robotization and IoT. BDA and IoT are also considered the most interesting ones. Similar conclusions are drawn from other studies and coincide with the technological point of view that I4.0 is based on IoT and hyperconnectivity. At the same time, it can be concluded that, in terms of technology, the surveyed companies are prepared for the challenges of I4.0. A limitation that has been pointed out in this area is that knowledge about existing technological solutions is not widespread.

It is worth noting that despite the indicated limitations, most of the respondents have a high level of conviction that the implementation of I4.0 will bring positive economic results and may contribute to the increase in the competitiveness of enterprises [1].

In the article, the authors examined the opinions of I4.0 experts on the most important barriers and challenges related to the implementation and feasibility of I4.0 in the companies they represent.

The positive experience of respondents in the area of I4.0 as well as their knowledge of the subject most probably had an effect on the analysis. Due to the uneven level of development of I4.0 in Poland and to the fact that this is a relatively new phenomenon, it is difficult to clearly indicate its consequences at the moment. Implementation of I4.0 offers new opportunities for enterprises, but also requires using relevant business strategies. When creating the I4.0 development strategy, one should take into account the constraints and to conduct research on the possibilities, difficulties, and challenges I 4.0 may offer in various aspects, taking into account variables from a wide range of areas, including those technological, economic, and social. Analysis of the impact on different areas of business and economy and the identification of opportunities and risks can make it easier for individual entities to decide whether it is worth going towards I4.0. The development of targeted tools for assessing the degree of implementation of I4.0 tailored to the requirements of enterprises should include the idea of sustainable development, which allows for a holistic view of all processes taking place. The results of the study show some constraints and challenges that arise in the implementation of I4.0 in the 
context of SMEs, and they can be relevant for both industry researchers, practitioners, and managers. The subject matter is important and reflects current trends and interests in industry and economy. An additional advantage of the article is its empirical nature. To date, there are not many studies in this field in Poland. The paper creates a framework for future research in order to analyze the implementation of I4.0.

The conducted type of research has its limitations, which need to be mentioned. The sample size was small, which was largely due to the character of the pilot study, the low level of I4.0 development in Poland, and the difficulty in reaching respondents. Therefore, there was a lack of hard data to conduct an objective quantitative analysis. The increase in the credibility of the results was achieved by the deliberate selection of a sample and a careful recruitment of the survey participants to include individuals directly responsible for the transformation toward I4.0 in their workplace. The study was limited to only one region in Poland. It is worth mentioning, however, that this is the most industrialized region with a dominant automotive industry, which encourages the development of I4.0. Further analysis of barriers and challenges could include a more accurate measurement of the importance of each factor and the correlations that occur between them. More attention should be paid, in particular, to the social, organizational, and environmental (ecological) conditions at individual stages of the implementation and feasibility of I4.0. The study of the impact of I4.0 on sustainable development should be deepened taking into account the size of enterprises, economic sectors, and industries. Further research can also concentrate on the level of socio-technical interaction between all the actors and resources involved in manufacturing, especially those areas where automation and robotics are particularly effective and where the introduction of I4.0 solutions affects the creation of new jobs and/or the elimination of previously existing ones. In the latter context, the focus could be on creating the employee I4.0 competence model and tools for competence profiling.

We are convinced that a carefully organized and managed pilot study has the potential to increase the quality of the extended research as results from such studies can inform subsequent parts of the research process.

Author Contributions: Conceptualization, A.P., A.H., M.W., and D.G.; methodology, A.H., and D.G.; formal analysis, A.P., A.H., M.W., and D.G.; investigation, A.P., and M.W.; resources, A.P., A.H., M.W., and D.G.; data curation, A.P., A.H., M.W., and D.G.; writing-original draft preparation, A.P., A.H., M.W., and D.G.; writing-review and editing, A.H. and D.G.; visualization, M.W.; supervision, A.H., and D.G; project administration, A.P., A.H., M.W., and D.G.; funding acquisition, D.G. All authors have read and agreed to the published version of the manuscript.

Funding: The publication is financed within the framework of the program titled "Dialogue" introduced by the Minister of Science and Higher Education between 2016-2019.

Conflicts of Interest: The authors declare no conflict of interest.

\section{References}

1. Stankovic, M.; Gupta, R.; Figueroa, J.E.; Calzadilla-Sarmiento, B.; Memedovic, O.; Authried, O.; Rueth, T. Industry 4.0. Opportunities Behind the Challenge, Background Paper, UNIDO 2017. Available online: https://www.unido.org/sites/default/files/files/201711/UNIDO\%20Background\%20Paper\%20on\% 20Industry\%204.0_27112017.pdf (accessed on 5 April 2020).

2. Kagermann, H.; Wahlster, W.; Helbig, J. Recommendation for Implementing the Strategic Initiative Industrie 4.0. In Final Report of the Industrie 4.0 Working Group; Communication Promoters Group of the Industry-Science Research: Frankfurt, Germany, 2013; Available online: https://www.din.de/blob/76902/ e8cac883f42bf28536e7e8165993f1fd/recommendations-for-implementing-industry-4-0-data.pdf (accessed on 5 April 2020).

3. Wagner, T.; Herrmann, C.; Thiede, S. Industry 4.0 Impacts on Lean Production Systems. Procedia Cirp 2017, 63, 125-131. [CrossRef]

4. Alcacer, V.; Cruz-Machado, V. Scanning the Industry 4.0: A Literature Review on Technologies for Manufacturing System. Eng. Sci. Technol. Int. J. 2019, 22, 899-919. Available online: https://reader.elsevier.com/reader/sd/pii/S2215098618317750?token=AB6D8DE2B63AF115D6B64DC4FD2F947 
A93E4F7C829B91BD0460ED21375C541705766EDBF5CF63C6C7F2F424835BFA719 (accessed on 20 February 2020). [CrossRef]

5. Grieco, A.; Caricato, P.; Gianfreda, D.; Pesce, M.; Rigon, V.; Tregnaghi, L.; Voglino, A. An Industry 4.0 Case Study in Fashion Manufacturing. Procedia Manuf. 2017, 11, 871-877. [CrossRef]

6. Motyl, B.; Baronio, G.; Uberti, S.; Speranza, D.; Filippi, S. How will Change the Future Engineer's Skills in the Industry 4.0 Framework? A Questionnaire Survey. Procedia Manuf. 2017, 11, 1501-1509. [CrossRef]

7. Birkel, H.S.; Veile, J.W.; Müller, J.M.; Hartmann, E.; Voigt, K. Development of a Risk Framework for Industry 4.0 in the Context of Sustainability for Established Manufacturers. Sustainability 2019, 11, 384. [CrossRef]

8. Müller, J.M.; Kiel, D.; Voigt, K.I. What Drives the Implementation of Industry 4.0? The Role of Opportunities and Challenges in the Context of Sustainability. Sustainability 2018, 10, 247. [CrossRef]

9. Müller, J.M.; Buliga, O.; Voigt, K.I. Fortune Favors the Prepared: How SMEs Approach Business Model Innovations in Industry 4.0. Technol. Forecast. Soc. 2018, 132, 2-17. [CrossRef]

10. Lu, Y. Industry 4.0: A survey on technologies, applications and open research issues. J. Ind. Inf. Integr. 2017, 6, 1-10. [CrossRef]

11. Schwab, K. The Fourth Industrial Revolution; World Economic Forum: Cologny/Geneva, Switzerland, 2016; Available online: https://luminariaz.files.wordpress.com/2017/11/the-fourth-industrial-revolution-2016-21. pdf (accessed on 17 January 2020).

12. Vuksanović Herceg, I.; Kuč, V.; Mijušković, V.M.; Herceg, T. Challenges and Driving Forces for Industry 4.0 Implementation. Sustainability 2020, 12, 4208. [CrossRef]

13. Lasi, H.; Fettke, P.; Kemper, H.; Feld, T.; Hoffmann, M. Industry 4.0. Bus. Inf. Syst. Eng. 2014, 6, $239-242$. [CrossRef]

14. Stock, T.; Obernaus, M.; Kunz, S.; Khol, H. Industry 4.0 as an enabler for sustainable development: A qualitative assessment of its ecological and social potential. Process Saf. Environ. Prot. 2018, 118, 254-267. [CrossRef]

15. Piccarozzi, M.; Aquilani, B.; Gatti, C. Industry 4.0 in Management Studies: A Systematic Literature Review. Sustainability 2018, 10, 3821. Available online: https://www.mdpi.com/journal/sustainability (accessed on 17 January 2020). [CrossRef]

16. Daviesa, R.; Cooleb, T.; Smithc, A. Review of socio-technical considerations to ensure successful implementation of Industry 4.0. Procedia Manuf. 2017, 11, 1288-1295. [CrossRef]

17. Gerbert, P.; Lorenz, M.; Rüßmann, M.; Waldner, M.; Justus, J.; Engel, P.; Harnisch, M. The Future of Productivity and Growth in Manufacturing Industries. Available online: https://www.bcg.com/pl-pl/publications/2015/engineered_products_project_business_industry_4_ future_productivity_growth_manufacturing_industries.aspx (accessed on 13 April 2020).

18. Vermeulen, F. Industry 4.0: The Ultimate Guide. Available online: https://industryeurope.com/industry-4-0the-ultimate-guide/ (accessed on 13 April 2020).

19. Santos, C.; Mehrsai, A.; Barros, A.C.; Araújo, M.; Ares, E. Towards Industry 4.0: An overview of European strategic roadmaps. Procedia Manuf. 2017, 13, 972-979. [CrossRef]

20. Marr, B. The 4th Industrial Revolution Is Here-Are You Ready. Available online: https://www.forbes.com/ sites/bernardmarr/2018/08/13/the-4th-industrial-revolution-is-here-are-you-ready/\#ea01d4d628b2 (accessed on 28 March 2020).

21. PWC Raport. Opportunities and Challenges of the Industrial Internet. Available online: https://www.pwc. pl/pl/pdf/industry-4-0.pdf (accessed on 28 March 2020).

22. Wang, S.; Wan, J.; Li, D.; Zhang, C. Implementing Smart Factory of Industrie 4.0: An Outlook. Int. J. Distrib. Sens. Netw. 2016, 12, 3159805. [CrossRef]

23. Burmeister, C.; Lüttgens, D.; Piller, F.T. Business Model Innovation for Industrie 4.0: Why the "Industrial Internet" Mandates a New Perspective on Innovation. Die Unternehm. 2016, 70, 124-152. Available online: https://www.nomos-elibrary.de/10.5771/0042-059X-2016-2-124/business-model-innovation-for-industrie4-0-why-the-industrial-internet-mandates-a-new-perspective-on-innovation-volume-70-2016-issue-2 (accessed on 28 March 2020). [CrossRef] 
24. Arnold, C.; Veile, J.; Voigt, K.I. What Drives Industry 4.0 Adoption? An Examination of Technological, Organizational, and Environmental Determinants. In Proceedings of the International Association for Management of Technology (IAMOT) Conference, Birmingham, UK, 13-17 September 2020; Available online: https://www2.aston.ac.uk/aston-business-school/documents/IAMOT2018_paper_75.pdf (accessed on 17 April 2020).

25. Ibarra, D.; Ganzarain, J.; Igartua, J.I. Business model innovation through Industry 4.0: A review. Procedia Manuf. 2018, 22, 4-10. Available online: https://www.sciencedirect.com/science/article/pii/S2351978918302968 (accessed on 28 March 2020). [CrossRef]

26. Ślusarczyk, B. Industry 4.0: Are we ready? Pol. J. Manag. Stud. 2018, 17, 232-248. [CrossRef]

27. Stock, T.; Seliger, G. Opportunities of sustainable manufacturing in industry 4.0. Procedia Cirp 2016, 40, 536-541. [CrossRef]

28. Industry 4.0: Building the Digital Enterprise. Available online: https://www.pwc.com/gx/en/ industries/industrial-manufacturing/publications/assets/pwc-building-digital-enterprise.pdf (accessed on 18 April 2020).

29. Brettel, M.; Friederichsen, N.; Keller, M.; Rosenberg, M. How virtualization, decentralization and network building change the manufacturing landscape: An Industry 4.0 Perspective. Int. J. Mech. Ind. Sci. Eng. 2014, 8, 37-44.

30. Erol, S.; Jäger, A.; Hold, P.; Ott, K.; Sihn, W. Tangible Industry 4.0: A Scenario-Based Approach to Learning for the Future of Production. Procedia CiRp 2016, 54, 13-18. Available online: https://core.ac.uk/download/ pdf/81935937.pdf (accessed on 18 April 2020). [CrossRef]

31. Schuhmacher, J.; Hummel, V. Decentralized Control of Logistic Processes in Cyber-Physical Production Systems at the Example of ESB Logistics Learning Factory. Procedia CIRP 2016, 54, 19-24. [CrossRef]

32. Bonilla, S.; Silva, H.; Terra da Silva, M.; Franco Gonçalves, R.; Sacomano, J. Industry 4.0 and Sustainability Implications: A Scenario-Based Analysis of the Impacts and Challenges. Sustainability 2018, 10, 3740. [CrossRef]

33. Buhr, D. Social Innovation Policy for Industry 4.0; Friedrich-Ebert-Stiftung: Bonn, Germany, 2017; Available online: https://www.researchgate.net/profile/Daniel_Buhr2/publication/330970346_Social_Innovation_ Policy_for_Industry_40/links/5c5dd119299bf1d14cb4bf4f/Social-Innovation-Policy-for-Industry-40.pdf (accessed on 18 April 2020).

34. Peukert, B.; Benecke, S.; Clavell, J.; Neugebauer, S.; Nissen, N.F.; Uhlmann, E.; Lang, K.-D.; Finkbeiner, M. Addressing Sustainability and Flexibility in Manufacturing Via Smart Modular Machine Tool Frames to Support Sustainable Value Creation. Procedia CIRP 2015, 29, 514-519. [CrossRef]

35. Brettel, M.; Klein, M.; Friederichsen, N. The Relevance of Manufacturing Flexibility in the Context of Industrie 4.0. Procedia CIRP 2016, 41, 105-110. [CrossRef]

36. Brozzi, R.; Forti, D.; Rauch, E.; Matt, D.T. The Advantages of Industry 4.0 Applications for Sustainability: Results from a Sample of Manufacturing Companies. Sustainability 2020, 12, 3647. [CrossRef]

37. Elkington, J. Towards the Sustainable Corporation: Win-Win-Win Business Strategies for Sustainable Development. Calif. Manage. Rev. 1994, 36, 90-100. [CrossRef]

38. Lee, I.; Lee, K. The Internet of Things (IoT): Applications, investments, and challenges for enterprises. Bus. Horiz. 2015, 58, 431-440. [CrossRef]

39. Barreto, L.; Amaral, A.; Pereira, T. Industry 4.0 Implications in Logistics: An Overview. Procedia Manuf. 2017, 13, 1245-1252. [CrossRef]

40. Ajoudani, A.; Zanchettin, A.; Ivaldi, S.; Albu-Schäffer, A.; Kosuge, K.; Khatib, O. Progress and Prospects of the Human-Robot Collaboration. Auton. Robot. 2017, 42, 957-975. [CrossRef]

41. Rüßmann, M.; Lorenz, M.; Gerbert, P.; Waldner, M.; Justus, J.; Engel, P.; Harnisch, M. Industry 4.0: The Future of Productivity and Growth in Manufacturing; BCG: Boston, MA, USA, 2015.

42. Veza, I.; Mladineo, M.; Gjeldum, N. Managing Innovative Production Network of Smart Factories. IFAC PapersOnLine 2015, 48, 555-560. [CrossRef]

43. Bonekamp, L.; Sure, M. Consequences of Industry 4.0 on Human Labour and Work Organisation. J. Bus. Media Psychol. 2015, 6, 33-40.

44. Kazancoglu, Y.; Ozkan-Ozen, Y.D. Analyzing Workforce 4.0 in the Fourth Industrial Revolution and proposing a road map from operations management perspective with fuzzy DEMATEL. J. Enterp. Inf. Manag. 2018, 31, 891-907. [CrossRef] 
45. David, D.; Lynn, J.S.; Ellis, A. (Eds.) Rational and Irrational Beliefs. Research, Theory, and Clinical Practise; Oxford University Press: Oxford, UK, 2010; pp. 4-8.

46. Baker, T.L. Doing Social Research, 2nd ed.; McGraw-Hill: New York, NY, USA, 1994.

47. Eisenhardt, K.M.; Graebner, M.E. Theory Building from Cases: Opportunities and Challenges. AMJ 2007, 50, 25-32. [CrossRef]

48. Edmondson, A.C.; Mcmanus, S.E. Methodological fit in management field research. AMR 2007, 32, $1246-1264$. [CrossRef]

49. Schnall, A.H.; Wolkin, A.; Nakata, N. Methods: Questionnaire Development and Interviewing Techniques. In Disaster Epidemiology, Methods and Applications; Academic Press: Cambridge, MA, USA, 2018; pp. 101-108. [CrossRef]

50. Ministry of Development Poland. Available online: https://miir.bip.gov.pl/organy-pomocnicze-i-doradcze/ zespol-ds-transformacji-przemyslowej.html (accessed on 18 April 2020).

(C) 2020 by the authors. Licensee MDPI, Basel, Switzerland. This article is an open access article distributed under the terms and conditions of the Creative Commons Attribution (CC BY) license (http://creativecommons.org/licenses/by/4.0/). 